\title{
Introducción de la serie "Puesta al día": El enfermo crítico con infección grave
}

\section{Introduction series "Up-date". The critical patient with severe infection}

\author{
M. Palomar Martínez ${ }^{\mathrm{a}, *}$ y R. Zaragoza Crespo ${ }^{\mathrm{b}}$
}

${ }^{a}$ ENVIN-HELICS, Sección Medicina Intensiva, Hospital Universitario Vall d'Hebrón, Barcelona, España

${ }^{\mathrm{b}}$ Grupo de Trabajo de Enfermedades Infecciosas, Sociedad Española de Medicina Intensiva, Crítica y Unidades Coronarias, Medicina Intensiva, Hospital Universitario Dr. Peset, Valencia, España

Recibido el 7 de diciembre de 2009; aceptado el 10 de diciembre de 2009

Disponible en Internet el 1 de abril de 2010

Las infecciones comunitarias graves, así como la infección nosocomial complicada, son una de las principales razones de ingreso en la unidad de cuidados intensivos ( $\mathrm{UCl})$. Por otra parte, la infección adquirida en la UCI es una de las complicaciones más frecuentes y graves de los pacientes durante su estancia en la unidad. La necesidad de mantener «al día» la información más relevante en los aspectos más destacados de esta enfermedad en nuestros pacientes justifica la actual serie.

El Grupo de Trabajo de Enfermedades Infecciosas (GTEI) de la Sociedad Española de Medicina Intensiva, Crítica y Unidades Coronarias (SEMICYUC), uno de los grupos pioneros en la Sociedad, ha desarrollado desde su inicio una actividad investigadora que pretendía responder muchos de los interrogantes específicos referentes a la enfermedad infecciosa del paciente crítico. La información obtenida ha permitido mejorar la atención a los pacientes con infección así como establecer estrategias de prevención en el resto. El reconocimiento al trabajo, tanto individual como colectivo, de los intensivistas españoles dedicados a la enfermedad infecciosa ha traspasado nuestras fronteras, y algunos de los proyectos del GTEl se han plasmado en un importante número de publicaciones de prestigio.

Desde 1994, el estudio de incidencia ENVIN-UCI ha controlado las infecciones relacionadas con el uso de dispositivos que se desarrollan durante la estancia en los servicios de Medicina Intensiva así como el uso de antimicrobianos, tanto el tipo utilizado como las indicaciones, la duración o la idoneidad de éstos. Este estudio ha aportado un notable conocimiento del problema de las IN en los hospitales españoles, y sus resultados son de referencia en la materia. También ha sido relevante su contribución a la formación y a la sensibilización del personal sanitario sobre el problema. Un aspecto relacionado con la gestión de los servicios al que ENVIN puede contribuir significativamente es la obtención periódica de indicadores de calidad de la asistencia que permitan que tanto la unidad como el hospital o la institución responsable puedan valorar la situación y observar puntos de mejora. La primera puesta a punto revisará, sobre la base de estos datos, la epidemiología y el impacto de las infecciones adquiridas en la UCl.

La atención segura a nuestros pacientes es en la actualidad una exigencia profesional y social a la que no puede darse la espalda. La SEMICYUC en colaboración con el Ministerio de Sanidad, Consumo y Política Social (MSCPS) y la Organización Mundial de la Salud (OMS) ha liderado, a partir de una iniciativa del GTEI, un ambicioso proyecto que pretende no sólo reducir las bacteriemias relacionadas con catéteres, sino crear grupos de trabajo con capacidad de

*Autor para correspondencia.

Correo electrónico: mpalomar@vhebron.net (M. Palomar Martínez). 
liderazgo que puedan seguir programas de prevención de otras infecciones nosocomiales y reforzar la cultura de la seguridad en el tratamiento del paciente crítico. La segunda puesta a punto abordará la prevención no sólo de las bacteriemias, sino de las infecciones adquiridas en la $\mathrm{UCl}$ en general incluyendo aspectos técnicos y de seguridad.

Uno de los principales problemas con los que se enfrentan los intensivistas en el tratamiento de las infecciones en la $\mathrm{UCl}$ es la progresiva resistencia de los agentes etiológicos. Esta resistencia no sólo afecta a las infecciones adquiridas en la $\mathrm{UCl}$, sino que cada vez es más frecuente que los pacientes ingresen, bien procedentes del mismo hospital, de centros de larga estancia o de la comunidad, con infecciones causadas por microorganismos resistentes, y conlleva una mayor mortalidad y consumo de recursos hospitalarios. La tercera actualización revisará la situación actual de la multirresistencia con especial énfasis en las unidades de nuestro país.

Por otra parte, la aparición de nuevos antibióticos con mayor espectro y potencia que hasta ahora había solucionado el problema de la resistencia se ha frenado y muy especialmente respecto a los antimicrobianos necesarios para tratar las infecciones por bacilos gramnegativos. Dado que uno de los factores que más influencia tienen en la evolución es la administración temprana de un tratamiento antibiótico empírico adecuado, el incremento de la resistencia y la falta de nuevas armas terapéuticas hacen imprescindible la elaboración y el seguimiento de una política antibiótica que mejore la atención individual de cada paciente, a la vez que preserve la utilidad de los antimicrobianos que deberán prescribirse en el futuro, tema que abordará la cuarta puesta a punto.

Como se ha comentado previamente, la infección comunitaria grave es una de las principales causas de ingreso en los servicios de Medicina Intensiva y nuestro grupo de trabajo las ha estudiado ampliamente; las publicaciones derivadas de estos estudios se han convertido en citas de referencia internacional que a buen seguro se comentarán en la quinta puesta al día. Asimismo, la atención de este tipo de enfermos ha conllevado que los «intensivistas salgan de las $\mathrm{UCl}_{\text {» }} \mathrm{y}$ atiendan a los enfermos dondequiera que estén, y amplíen el campo de acción de nuestra especialidad.

Aproximadamente un $10 \%$ de los episodios infecciosos en una UCI tiene como etiología Candida species, y la mayoría de estos episodios son de origen nosocomial. Esta incidencia puede estar infraestimada debido al hecho de que al menos un $4 \%$ de los pacientes que fallecen en nuestras unidades presenta una infección fúngica no diagnosticada hasta el examen post mórtem. Aunque menos frecuente, en los últimos años se han descrito en nuestro medio otras infecciones fúngicas, como aspergilosis, especialmente en pacientes con obstrucción crónica al flujo aéreo y tratamiento crónico con corticoides, y las causadas por otros hongos filamentosos y levaduras emergentes, como Trichosporon asahi, Saccharomyces boulardii, Hansenula anomala, Dipodascus capitatus o Rhizopus microsporus, todos ellos conllevan una alta morbilidad y un mal pronóstico. Estudios realizados en el seno de nuestro grupo de trabajo (EPCAN, CAVA, entre otros) han hecho que el «Candida score» se convierta en el predictor de infección candidiásica en el enfermo crítico más potente y aún más referenciado de los descritos hasta el momento, tal y como se revisará en la sexta puesta al día por su creador.

La capacidad de adaptación a la realidad cambiante junto con la visión de futuro han permitido crear un registro de una nueva entidad: la infección por el virus $\mathrm{H} 1 \mathrm{~N} 1$, proyecto pionero en Europa que ha permitido conocer nuestros propios datos de esta nueva y amenazante epidemia desde su inicio, gracias a la iniciativa y de nuevo, el trabajo del GTEI y SEMICYUC. Otro tipo de infecciones víricas presentes tanto en pacientes previamente sanos como en pacientes inmunodeprimidos son las enfermedades que precisan en ocasiones ingreso en nuestras unidades. Todo ello, junto con el posible papel etiológico de los virus en la neumonía asociada a ventilación mecánica, se discutirá ampliamente en la séptima entrega de la serie.

\section{Agradecimientos}

Queremos agradecer a los 26 autores de esta serie, todos ellos miembros de la Sociedad e integrantes del GTEI, su esfuerzo, dedicación y entrega a este proyecto $y$, finalmente, a la revista Medicina Intensiva por darnos la oportunidad de poder revisar para la sociedad y para el mundo del enfermo crítico los temas más candentes en la actualidad en el paciente con infección grave. 